\title{
Captura la idea: Actividad lúdica para la enseñanza y fortalecimiento del pensamiento de diseño
}

Capture the idea: Playful activity for teaching and strengthening design thinking

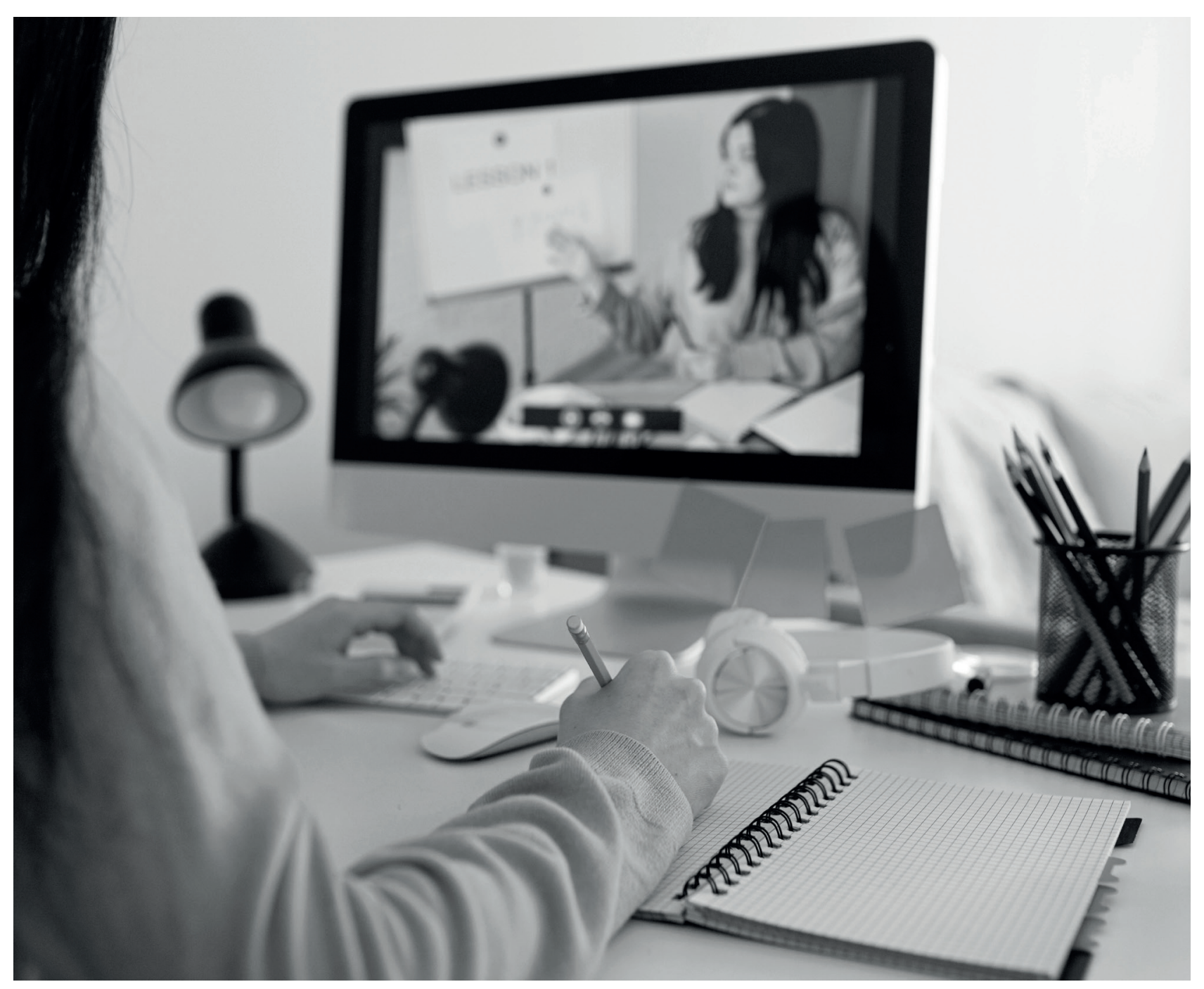




\title{
Captura la idea: Actividad lúdica para la enseñanza y fortalecimiento del pensamiento de diseño ${ }^{1}$
}

\author{
Capture the idea: Playful activity for teaching and strengthening \\ design thinking
}

\author{
Leidy Tatiana Alvao-Saenz², Juliana Quintero-Salazar³, Angie Marcela Ramírez Rubio ${ }^{4}$
}

Artículo recibido en abril 28 de 2020; artículo aceptado en julio 22 de 2020

\begin{abstract}
Este artículo puede compartirse bajo la Licencia Creative Commons Atribución-NoComercial-Compartirlgual 4.0 Internacional_y se referencia usando el siguiente formato: Alvao-Saenz, L. T., Quintero-Salazar, J. y Ramírez, A. M. (2021). Captura la idea: Actividad lúdica para la enseñanza y fortalecimiento del pensamiento de diseño. I+D Revista de Investigaciones, 16(1), 28-44. http://dx.doi.org/10.33304/
\end{abstract} revinv.v16n1-2021003.

\begin{abstract}
Resumen
Con la finalidad de favorecer la percepción del método enseñanza-aprendizaje activo para el tema del diseño del producto en la materia Administración de Operaciones I, se propone el diseño de una actividad lúdica llamada "Captura la idea" y un ejercicio para su validación. Para el diseño de la lúdica se utilizó la metodología Gamificación Canvas, y el referente teórico de la temática se basó en el modelo Mindshake Design Thinking Evolution $6^{2}$. Para la validación, se realizó un estudio causal y cuasiexperimental para una muestra de 20 estudiantes con quienes se aplicaron dos encuestas tipo Likert. Los resultados permiten aceptar la hipótesis propuesta, y se concluye que el uso de esta estrategia mejora en promedio un $15 \%$ la percepción del alumno. Adicionalmente, se evidenció que los estudiantes sienten que la clase es más estimulante, agradable y llamativa en comparación con una clase netamente magistral.
\end{abstract}

Palabras clave: Juego educativo, design thinking, diseño del producto, creatividad, lúdicas.

\section{Abstract}

This research study aims to present the design of the playful activity "Capture the Idea", as well as its validation, in an attempt to prove that this active learning activity favors the perception of the teaching-learning method in the subject Administración de Operaciones I in the topic of product design. For the design, the methodology Gamificación Canvas was used, and it was based on the Mindshake Design Thinking Evolution $6^{2}$ model. For its validation, a causal and quasi-experimental study was carried out for a sample of 20 students where two Likert surveys were applied. The

\footnotetext{
$\overline{1}$ Artículo de investigación, de enfoque mixto, resultado de un trabajo de grado en curso, perteneciente al área de ingeniería, subárea operaciones y procesos, desarrollado en el Grupo de Investigación GINNOVA, programa de Ingeniería Industrial, Universidad de Ibagué (Colombia). Dirección: carrera 22 calle 67 B, Av. Ambalá, Ibagué, 730002, Colombia, PBX: +57 (8) 2760010 . Fecha de inicio: febrero de 2020. Fecha de finalización: septiembre de 2020.

${ }^{2}$ Estudiante de Ingeniería Industrial, Universidad de Ibagué. Vinculada al programa de Ingeniería Industrial, Universidad de Ibagué, (Ibagué, Colombia), Dirección: carrera 22 calle 67, PBX: +57(8) 2760010. ORCIR ID: https://orcid.org/0000-0001-5946-6516. Correo electrónico institucional: 2320162073@estudiantesunibague.edu.co.

${ }^{3}$ Estudiante de Ingeniería Industrial, Universidad de Ibagué. Vinculada al programa de Ingeniería Industrial, Universidad de Ibagué, (Ibagué, Colombia), Dirección: carrera 22 calle 67, PBX: +57(8) 2760010. ORCIR ID: https://orcid.org/0000-0002-1803-6066. Correo electrónico institucional: 2320162058@estudiantesunibague.edu.co.

${ }^{4}$ Especialista en Evaluación y Desarrollo de Proyectos, Universidad del Rosario. Vinculada al Grupo de investigación GINNOVA, Programa de Ingeniería Industrial, Universidad de Ibagué (Ibagué, Colombia), Dirección: carrera 22 calle 67 PBX: +57(8) 2760010. ORCID ID: https://orcid. org/0000-0001-6390-4849. Correo electrónico institucional: angie.ramirez@unibague.edu.co.
} 
Leidy Tatiana Alvao-Saenz, Juliana Quintero-Salazar, Angie Marcela Ramírez Rubio

Captura la idea: Actividad lúdica para la enseñanza y fortalecimiento del pensamiento de diseño

results allow us to accept the proposed hypothesis, concluding that the use of this strategy improves the student's perception in a positive way by an average of 15\%. Additionally, it was evident that students feel that the class is more stimulating, enjoyable, and engaging compared to a purely masterful class.

Keywords: Educational game, design thinking, product design, creativity, playful.

\section{Introducción}

A día de hoy el mundo empresarial se ha vuelto más competitivo y se hace necesario innovar continuamente. Las empresas necesitan rediseñar y mejorar sus procesos para que sean más eficientes y generen una rentabilidad mayor. A causa de esto, los profesionales, y en especial los ingenieros industriales, tienen un papel crucial en la creación de valor en los procesos y productos, de forma que estos permitan responder de manera adecuada a las necesidades de los usuario o clientes (Aguilar-Fernández et al., 2017).

Por ello, la capacidad de crear e innovar se ha convertido en una competencia clave para la sociedad del siglo XXI. Ante esto, el pensamiento de diseño se convierte en un aspecto relevante, dado que es una competencia que todo ingeniero industrial debería tener en un alto grado de desarrollo luego de terminar su pénsum académico. Sin embargo, para el caso de estudio, esta competencia se ha tratado de forma indirecta y teórica al abordar el tema del diseño del producto, por lo que para algunos estudiantes puede resultar un poco tedioso e incomprensible. Por este motivo, se diseñó la lúdica "Captura la idea", que permite a los alumnos interiorizar cada una de las fases del diseño de una solución, y fortalecer sus competencias comunicativas y de trabajo en equipo.

Es importante aclarar que "todos somos seres creativos, pero la práctica y el desarrollo de esta habilidad, mediante técnicas, ayuda a mejorar, estimular la generación de ideas, resultados creativos y la creación de alternativas diferentes a problemas convencionales" (Rodríguez y Rodríguez, 2013).

El diseño del producto se aborda desde diferentes perspectivas, una de ella es el pensamiento de diseño conocido en inglés como design thinking (DT), que, de acuerdo con Tschimmel et al. (2017), "es un método para generar ideas innovadoras que centra su eficacia en entender y dar solución a las necesidades reales de los usuarios. Proviene de la forma en la que trabajan los diseñadores de producto".

Para el DT se han desarrollado previamente lúdicas con el objetivo de dar a conocer la metodología DT en la industria actual (Barreto et al., 2019; Ruiz et al., 2015), pues esta metodología facilita y mejora los procesos de creación y desarrollo de productos y servicios por medio de prototipos factibles y confiables, construidos con nuevas tecnologías, que permitan estar dentro de las tendencias y estándares internacionales (Barreto et al., 2019).

La lúdica "Captura la idea" se diferencia de las actividades lúdicas previas principalmente en el método de DT implementado. El modelo más reconocidoy convencional es el de innovation-design-engineering-organization (IDEO). La metodología utilizada en "Captura la idea" está basada en el modelo $6 \mathrm{E}$, el cual es poco utilizado pero innovador.

El objetivo de esta investigación es diseñar y validar una herramienta pedagógica sobre la temática de diseño de producto, para generar una mayor motivación e interés en los estudiantes sobre este aspecto. Con este propósito en mente, se planteó la siguiente hipótesis:

La actividad de aprendizaje activo con enfoque lúdico "Captura la idea" favorece la percepción del método enseñanza-aprendizaje en la materia de núcleo profesional de Ingeniería Industrial Administración de Operaciones I.

\section{Marco referencial}

El éxito de un país en la actualidad tiene una fuerte relación con la capacidad de producir (productos/ servicios) de forma competitiva en un mercado cada vez más globalizado. Esto requiere infraestructura para educar, alimentar, brindar productos y servicios básicos, prestar servicios de salud, de esparcimiento, culturales, entre otros. Igualmente requiere procesos y sistemas que generen productos y servicios competitivos y de calidad que sean valorados por el mercado nacional e internacional (Ramírez, 2019).

Dada esta tendencia, el pensamiento de diseño es fundamental para los ingenieros, puesto que la mayoría de sus "actividades profesionales consisten en crear materiales, estructuras, maquinarias o sistemas que sean la solución para muchos de los problemas que se presentan en el desarrollo de la humanidad" (Ramírez, 2019). En consecuencia, es importante definir la creatividad. Según Boden (1998), esta se concibe como:

Una característica fundamental de la inteligencia humana en general. Está cimentada en capacidades habituales, tales como la asociación de ideas, recuerdos, percepción, pensamiento analógico, búsqueda de estructuras, etc. Implica no solo una dimensión cognitiva (la generación de nuevas ideas) sino también la motivación y la 
Leidy Tatiana Alvao-Saenz, Juliana Quintero-Salazar, Angie Marcela Ramírez Rubio Captura la idea: Actividad lúdica para la enseñanza y fortalecimiento del pensamiento de diseño

emoción, y está vinculada al contexto cultural y ciertos factores de personalidad. (p. 347)

Una de las técnicas más reconocidas en el ámbito mundial es el DT, la cual, como afirman Pombo y Tschimmel (2005), "se basa en la capacidad del diseñador para considerar al mismo tiempo las necesidades humanas y nuevas visiones de vivir bien, el material disponible, tiempo y recursos, y las limitaciones y oportunidades de un proyecto o negocio".

Se debe agregar que el DT ha tenido una notable evolución. Consecuencia de ello es que en la actualidad existen diversas metodologías para su aplicación. Algunos de los modelos más conocidos son:

Modelo 3I de IDEO: Se conforma de tres fases: inspiración, ideación e implantación (Brown y Wyatt, 2010).

Modelo del Instituto Hasso-Plattner: Se divide en seis pasos, los cuales son comprender, observar, punto de vista, idear, prototipar y evaluar (Rauth et al., 2010).

Modelo Mindshake Design Thinking, Evolution $6^{2}$ (E.6²): Se constituye de seis partes: aparición, empatía, experimentación, elaboración, exposición y extensión (Tschimmel et al., 2017).

Dado a lo anterior, se identificaron lúdicas aplicadas a la metodología de DT (ver Tabla 1).

Tabla 1

Antecedentes lúdicos en la misma temática

\begin{tabular}{|c|c|}
\hline Autores & Descripción \\
\hline Ruiz et al., 2015 & $\begin{array}{l}\text { Ayuda a comprender herramientas empleadas } \\
\text { en la metodología del diseño (técnicas de DT), } \\
\text { para facilitarle la labor tanto al profesor como } \\
\text { a los alumnos a la hora de dar soluciones } \\
\text { creativas. Permite además desarrollar las } \\
\text { competencias transversales de innovación, } \\
\text { creatividad y emprendimiento. }\end{array}$ \\
\hline Barreto et al., 2019 & $\begin{array}{l}\text { Fortalece la aplicación del DT al incentivar la } \\
\text { utilización de nuevas competencias genéricas, } \\
\text { como la creatividad, el trabajo sistémico y el } \\
\text { trabajo en equipo. Además, interioriza cada } \\
\text { uno de los pasos propuestos por ella: generar la } \\
\text { empatía, definir el problema, generar posibles } \\
\text { soluciones y modelar y evaluar los prototipos. }\end{array}$ \\
\hline
\end{tabular}

Fuente: Autores

\section{Metodología}

Este apartado se divide en dos secciones (ver Figura 1). La primera está relacionada con el diseño de la lúdica y los elementos que se contemplaron, y la segunda hace referencia a la validación de la estrategia con su respectivo proceso de análisis de datos para probar estadísticamente la hipótesis planteada.

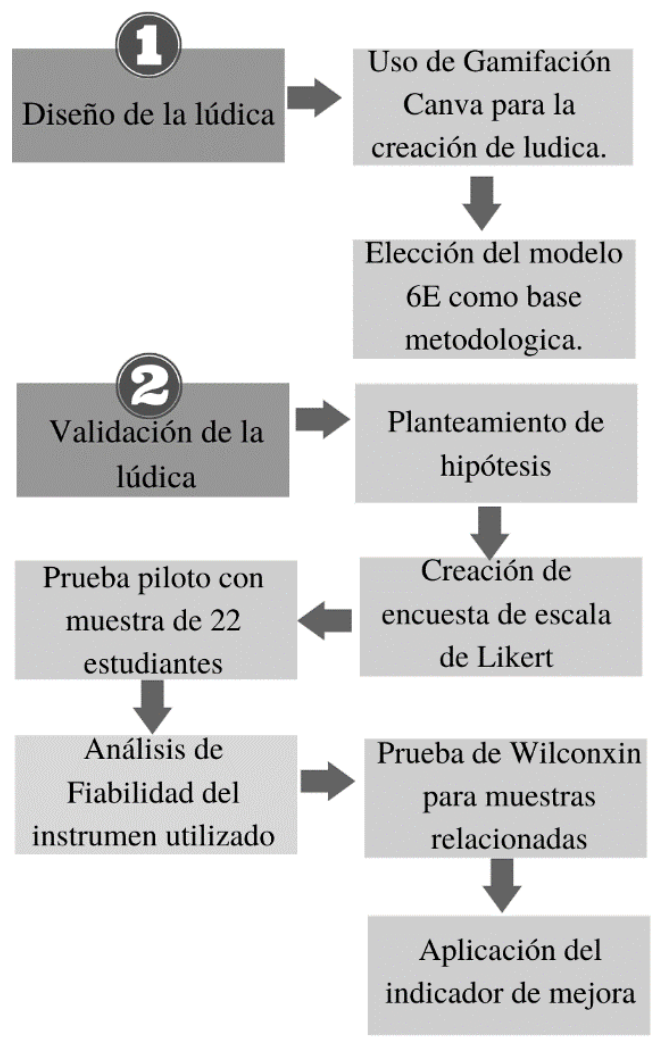

Figura 1. Descripción de la metodología. Fuente: Autores.

\section{Fase 1. Diseño de la lúdica}

Para el diseño de la actividad lúdica se siguió la metodología de Gamificación Canvas propuesta por la Institución Tecnológica de Monterrey, de México. Se plasmaron en el lienzo de gamificación las ideas sobre los elementos de juego, componentes y recursos que se deseaban incorporar, así como los comportamientos que esperaba ver en los jugadores (Escamilla et al., 2016). El procedimiento que se siguió fue el siguiente (Escamilla et al., 2016):

1. Describir el(los) objetivo(s) principal(es) que se busca(n) como resultado de la estrategia.

2. Definir el perfil de los jugadores.

3. Especificar los comportamientos y acciones que se esperan de los alumnos.

4. Listar los elementos a usar.

5. Explicar las mecánicas a utilizar (retos, competencia, recompensas, condiciones de gane, entre otros).

6. Detallar las dinámicas y las reglas del juego.

7. Establecer la forma de seguimiento al desarrollo de la lúdica.

8. Precisar los riesgos potenciales, aquellos incidentes negativos (de comportamiento, actitud o resultado).

9. Fijar los elementos de identidad visual y estética a la estrategia de aprendizaje.

Así mismo, se eligió el modelo Mindshake Design Thinking, Evolution $6^{2}$ (E $\left.6^{2}\right)$, desarrollado entre 2012- 
Leidy Tatiana Alvao-Saenz, Juliana Quintero-Salazar, Angie Marcela Ramírez Rubio

Captura la idea: Actividad lúdica para la enseñanza y fortalecimiento del pensamiento de diseño

2015 por Katja Tschimmel como base para la realización de la lúdica. Dicho modelo se ha aplicado tanto en el desarrollo de productos y servicios como en talleres, sesiones de coaching, proyectos de investigación y lecciones de metodología, haciendo alusión a este último uso, ya que es el más indicado para la aplicación de una lúdica. Su nombre $6 \mathrm{E}$ se debe a la cantidad de fases que se especifican, las cuales se describen a continuación (Tschimmel et al., 2017):

1. Emergence/Aparición: Identificar una oportunidad o un reto.

2. Empathy/Empatía: Conocer el contexto y definir el proyecto.

3. Experimentation/Experimentación: Generar ideas y desarrollar conceptos.

4. Elaboration/Elaboración: Materialización y validación de la solución.

5. Exposition/Exposición: Comunicación de nuevos conceptos y solución.

6. Extensión/Extensión: Poner las cosas en marcha.

Cabe resaltar que, para la segunda fase, en la lúdica diseñada se utilizó el mapa de empatía adaptado por Valdrich y Cândido (2018). De igual forma, para la última etapa (extensión) se empleó el modelo Business Canvas sugerido por Zandoval y Zilber (2014), como se puede observar en el Anexo I.

\section{Fase 2. Validación de la lúdica}

Para la validación de la actividad de aprendizaje activo con enfoque lúdico, se planteó la siguiente hipótesis causal. De acuerdo con Hernández et al. (2014), las hipótesis causales son las que afirman la(s) relación(es) entre dos o más variables y la manera en que se manifiestan, y además proponen un "sentido de entendimiento" de las relaciones.

Ha: La actividad de aprendizaje activo con enfoque lúdico "Captura la idea" favorece la percepción del método enseñanza-aprendizaje en la materia de núcleo profesional de Ingeniería Industrial Administración de Operaciones I en el tema del diseño del producto.

Ho: No hay influencia de la actividad de aprendizaje activo con enfoque lúdico en la percepción del método de enseñanza de aprendizaje en la materia de núcleo profesional de Ingeniería Industrial Administración de Operaciones I en el tema del diseño del producto.

Dado lo anterior, se decidió diseñar un instrumento de opinión de escala de Likert siguiendo la metodología propuesta por Albert (2007), quien afirma que la elaboración de un cuestionario está sujeto a las siguientes fases:

1. Describir la información que se requiere.

2. Elaborar las preguntas necesarias para obtener la información requerida.

3. Organizar las preguntas en el orden más adecuado.

4. Elaborar un instrumento para recolectar las respuestas.

5. Redactar las instrucciones para facilitar las respuestas.

6. Reproducir el cuestionario de acuerdo con el número de participantes.

Cabe resaltar que se tomó como base el cuestionario propuesto por Montoya et al. (2014). Además, para la elaboración del instrumento y su respectiva validación, se contó con el apoyo de dos expertos ingenieros industriales docentes del área de operaciones y procesos. Por consiguiente, se realizaron dos encuestas de percepción de técnica de Likert con 15 preguntas que permitieran conocer la percepción del método enseñanza-aprendizaje, con el fin de aplicarlas antes y después de la estrategia lúdica. Debido a que las preguntas son de elección múltiple de estimación, se definió la siguiente escala numérica donde 1 significa totalmente en desacuerdo; 2, en desacuerdo; 3, ni acuerdo ni desacuerdo; 4, de acuerdo, y 5, totalmente de acuerdo (Alaminos y Castejón, 2006).

Del mismo modo, se consideró el método de evaluación de lúdicas propuesto por Montoya (2014). Por lo tanto, se decidió aplicar una encuesta antes (ver Anexo II) y otra después (ver Anexo III) de la aplicación de Captura la idea en un grupo piloto de alumnos de Ingeniería Industrial de una universidad del departamento del Tolima que están cursando la asignatura Administración de Operaciones I, del semestre A 2020.

Para conocer la fiabilidad del instrumento luego de la aplicación de la prueba piloto, se utilizaron los parámetros establecidos por Kaplan y Saccuzzo (2006): "Mostrar resultados similares, libres de error, en repetidas mediciones". Dado esto, considerando el tipo de cuestionario desarrollado, se utilizó el alfa de Cronbach expuesto por Streiner (2003) para conocer la consistencia interna del cuestionario. Este coeficiente permite conocer "el grado en que los ítems, puntos o reactivos que hacen parte de una escala se correlacionan entre ellos, la magnitud en que miden el mismo constructo". Asimismo, se espera que el instrumento obtenga un valor entre 0,7 y 0,95 sugerido por Frias-Navarro (2019).

Tras comprobar que la consistencia interna es aceptable, se procedió a sumar las puntuaciones de los ítems y formar una puntuación total de una escala (FriasNavarro, 2019). Para ello, se utilizó el software SPSS en donde se calculó una nueva variable que se denominó Sumatoria Encuesta, la cual es la sumatoria de todos los puntajes obtenidos por individuo en el instrumento. Seguidamente, usando la función agrupación visual del mismo programa se clasificaron en 5 grupos los resultados, tal y como se observa en la Tabla 2, creando la variable Satisfacción para cada uno de los escenarios. Este 
Leidy Tatiana Alvao-Saenz, Juliana Quintero-Salazar, Angie Marcela Ramírez Rubio Captura la idea: Actividad lúdica para la enseñanza y fortalecimiento del pensamiento de diseño

ítem entonces permite ubicar el individuo en un nivel de satisfacción respecto al método enseñanza aprendizaje.

Tabla 2

Puntaje variable satisfacción

\begin{tabular}{cc}
\hline Puntaje & Categoría \\
\hline 0 a 15 & Muy insatisfecho \\
16 a 30 & Insatisfecho \\
31 a 45 & Ni satisfecho ni insatisfecho \\
46 a 60 & Satisfecho \\
61 a 70 & Muy satisfecho \\
\hline
\end{tabular}

Fuente: Autores.

Enseguida, se utilizó la prueba Wilcoxon para muestras relacionadas, ya que a los mismos participantes se les aplicó un cuestionario antes y después de la lúdica y los datos resultantes son ordinales. Dado esto, se utilizó nuevamente el software SPSS para este fin, considerando un alfa del $5 \%$. Finalmente, se realizó un promedio por cada pregunta pre-y poslúdica, y se halló la diferencia en puntuación entre la primera y segunda encuesta usando el siguiente indicador de mejora:

\section{(Desempeño poslúdica - Desempeño prelúdica) Desempeño prelúdica}

\section{Tipo de estudio}

La investigación es de enfoque mixto y carácter cuasiexperimental, debido que los sujetos no se asignan al azar a los grupos ni se emparejan, sino que estos ya están conformados antes del experimento (Hernández et al., 2014); en pocas palabras, son equipos intactos.

\section{Participantes}

Para la aplicación de la investigación se escogió un grupo de estudiantes que estaba cursando la asignatura de Administración de Operaciones I. Estos grupos normalmente tienen entre 20 a 30 estudiantes. La información requerida se recolectó en el laboratorio de Ingeniería Industrial con estudiantes de la asignatura Administración de Operaciones I, del semestre 2020 A de una universidad ubicada en la ciudad de lbagué. Para el desarrollo del estudio se tuvieron en cuenta los siguientes aspectos éticos:

- Garantizar el respeto a las personas que participan para la elaboración y aplicación de la actividad, protegiendo la dignidad humana.

- Asegurar la confiabilidad de cada uno de los participantes que ayudaron para la elaboración de la lúdica.

- Cumplir con todas las normas de la Institución.

\section{Materiales e instrumentos de la lúdica}

Para la realización de la lúdica se utilizaron los siguientes materiales (ver Anexo I):

- Video (este se puede encontrar en el siguiente enlace de la plataforma YouTube: https://youtu. be/5otTNOGbAHw)

- 24 vasos

- 8 tarjetas de las características de los clientes

- 8 fichas de deseos o necesidades de los clientes

- Mapa de empatía por cada grupo de trabajo.

- Hoja con un esquema para desarrollar el brainwriting

- Pliego de papel bond

- Marcadores de colores

- Plastilina

- Silicona

\section{Resultados}

\section{Estructura de la lúdica}

Inicialmente, y teniendo en cuenta la metodología Gamificación Canvas, se procedió a diligenciar el lienzo de Gamification Canvas para la elaboración de la lúdica, tal y como se muestra a continuación:

Objetivo: Reforzar la temática del diseño del producto de la asignatura de Administración de Operaciones I, a través del fortalecimiento del espíritu innovador y creativo en los estudiantes.

Perfil del jugador: La actividad lúdica tiene como posibles perfiles los siguientes jugadores: exploradores, socializadores, pensadores, triunfadores y revolucionarios.

Comportamientos esperados: Se busca que los estudiantes sean participativos y activos.

Componentes: La lúdica cuenta con los siguientes: fases, puntos, equipos y desbloqueo de contenidos.

Mecánicas: La actividad cuenta con las siguientes: suerte, adquisición de recursos, competencia, condiciones para ganar y realimentación.

Dinámicas: Los estudiantes tienen que realizar actividades que van a tener restricciones en el tiempo. La actividad cuenta con la siguiente narrativa:

El grupo empresarial T\&J se dedica a la fabricación y comercialización de productos de alta demanda a nivel nacional. T\&J desea aumentar el número de ventas mensuales; por tal razón, su junta directiva ha decidido ampliar sus mercados a través de la introducción de un nuevo producto innovador. Para cumplir con la meta propuesta, el grupo empresarial ha contratado a su equipo de trabajo para que 
Leidy Tatiana Alvao-Saenz, Juliana Quintero-Salazar, Angie Marcela Ramírez Rubio

Captura la idea: Actividad lúdica para la enseñanza y fortalecimiento del pensamiento de diseño

propongan el nuevo producto que se debe fabricary comercializar en el país.

Gestión: La lúdica cuenta con seis fases, cada una tiene actividades establecidas y un tiempo específico.

Riesgos potenciales: Uno de los riesgos es que los estudiantes no tengan buena disposición para la elaboración de la lúdica; por otro lado, el tiempo puede ser una limitación.

Estética: "Captura la idea" cuenta con ocho tipos de clientes, los cuales serán asignados aleatoriamente a cada equipo de trabajo por medio de tarjetas. Del mismo modo, se tienen 8 necesidades o deseos. Además, se presenta un modelo de brainwriting, mapa de empatía y el Modelo de Negocio Canvas.

A continuación, se describen los seis momentos en los que está dividida la lúdica, siguiendo la metodología 6E:

1. Emergente: En esta fase se presenta un video, el cual explica de una forma atractiva la definición, las características y los modelos existentes del DT. Posteriormente, se realiza una actividad con vasos, la cual consiste en que los participantes se posicionen alrededor de la mesa; seguidamente los vasos se colocan en posición boca abajo y el objetivo es que gracias al impulso de la mano se logren poner en posición boca arriba. De acuerdo con el orden en el que los grupos terminen, se realiza la asignación de las características de los clientes y necesidades.

2. Empatía: Aquí los estudiantes tienen que elaborar un mapa de empatía para ponerse en los zapatos de los clientes y así poder dar solución a las necesidades de cada cliente; para esto se debe resolver las siguientes preguntas; ¿qué piensa y siente?, ¿qué oye?, ¿qué ve?, ¿qué hace? y ¿qué dice?

3. Experimentación: Este es el momento de generación de ideas. Para este fin los estudiantes aplican brainwriting, el cual consiste en que cada participante debe escribir la mayor cantidad de ideas en dos minutos. Pasado este tiempo, se rota la hoja por cada persona que haya en el grupo de trabajo. Luego, se procede a calificar cada idea que generaron; la opción que gana es la que sea más factible, creativa y práctica para llevar a cabo.

4. Elaboración: Con la idea seleccionada, se procede a materializar la idea. Aquí los estudiantes tienen que elaborar un prototipo a partir de los materiales suministrados.

5. Exposición: En esta fase los estudiantes tienen que elaborar una historia para vender su idea (esto es conocido como storytelling). Aquí se brindan consejos y tips de cómo se debe realizar esta actividad de forma creativa.

6. Extensión: Los estudiantes tienen que elaborar un formato (Modelo Canvas simplificado) y pensar en todos los recursos y actividades que necesitan para hacer su idea realidad.

Finalmente, el grupo ganador se selecciona a través de una rúbrica elaborada por los diseñadores de la lúdica; esta considera el storytelling, la creatividad e innovación y el nombre del producto.

\section{Aplicación de la actividad}

El día dieciocho (18) de febrero del año 2020 se aplicó la lúdica en el grupo de Administración de Operaciones I (Anexo IV). La actividad se realizó con los 22 integrantes del salón de clases. De igual manera, se aplicaron dos encuestas: una prelúdica (Anexo II) y otra poslúdica (Anexo III).

\section{Validación de la actividad diseñada}

Inicialmente se procedió a realizar el coeficiente de alfa de Cronbach para cada uno de los instrumentos (ver Tablas 3 y 4). Los resultados son 0,944 y 0,898, y se encuentra entre 0,7 y 0,95 ; por tanto, se asume que el instrumento es confiable.

Tabla 3

Alfa de Cronbrach para la encuesta de la prelúdica

\begin{tabular}{cc}
\hline \multicolumn{2}{c}{ Estadísticas de fiabilidad } \\
\hline Alfa de Cronbach & N. ${ }^{\circ}$ de elementos \\
, 944 & 15 \\
\hline
\end{tabular}

Fuente: Autores.

Tabla 4

Alfa de Cronbrach para la encuesta de la poslúdica

\begin{tabular}{cc}
\multicolumn{2}{c}{ Estadísticas de fiabilidad } \\
\hline Alfa de Cronbach & N. ${ }^{\circ}$ de elementos \\
, 898 & 15 \\
\hline
\end{tabular}

Fuente: Autores.

Dado lo anterior, se halla la variable satisfacción pre- y pos, con la cual se analiza cada uno de los participantes respecto a qué tan complacido se encuentra con el método de enseñanza-aprendizaje. Dado esto, en la Figura 2 se observa que solo hay 7 participantes satisfechos y 11 muy satisfechos en la encuesta prelúdica, en tanto se encuentran 4 satisfechos y 18 muy satisfechos en la poslúdica (ver Figura 3). 
Leidy Tatiana Alvao-Saenz, Juliana Quintero-Salazar, Angie Marcela Ramírez Rubio Captura la idea: Actividad lúdica para la enseñanza y fortalecimiento del pensamiento de diseño

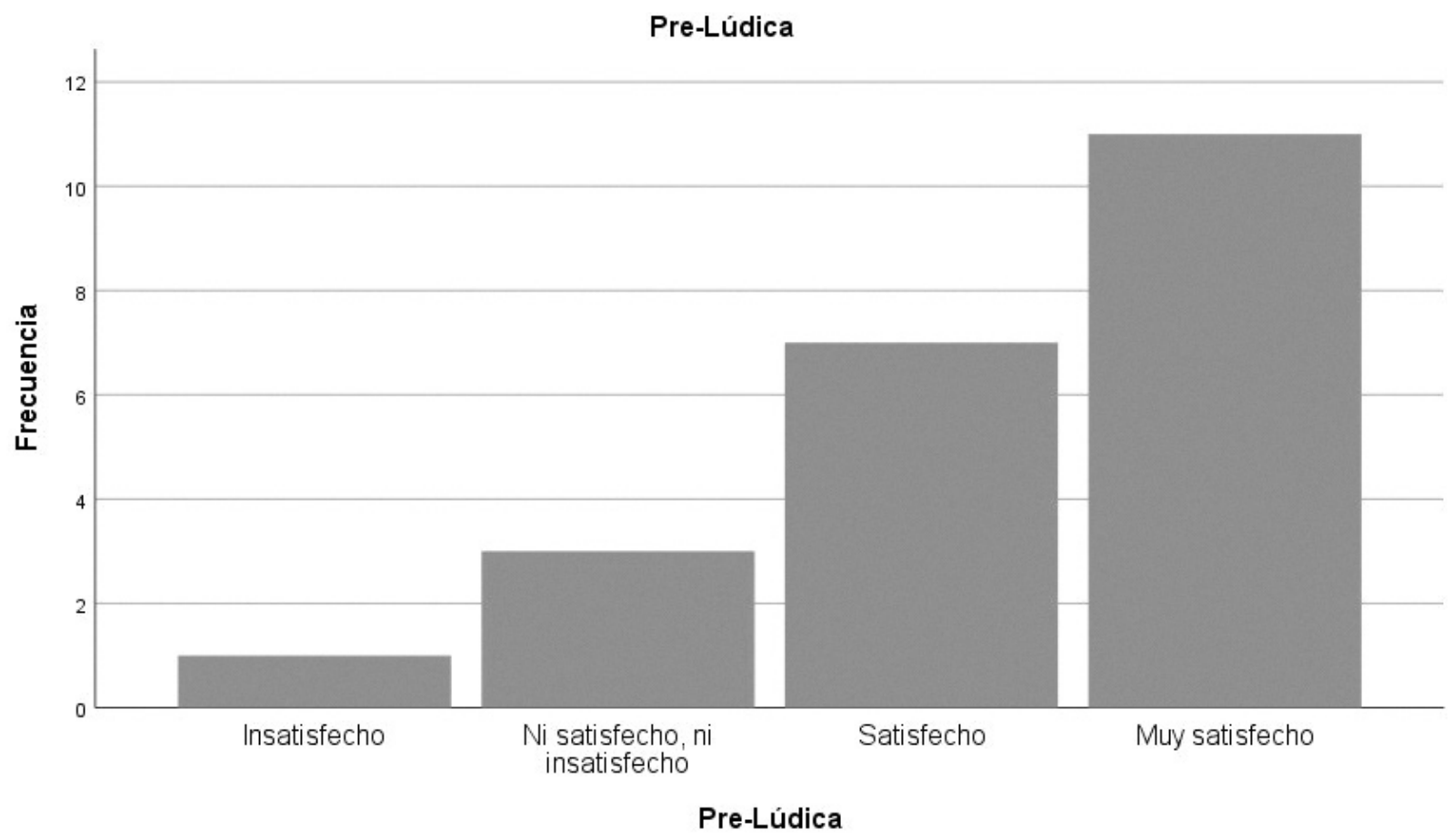

Figura 2. Frecuencia de la variable satisfacción prelúdica. Fuente: Autores.

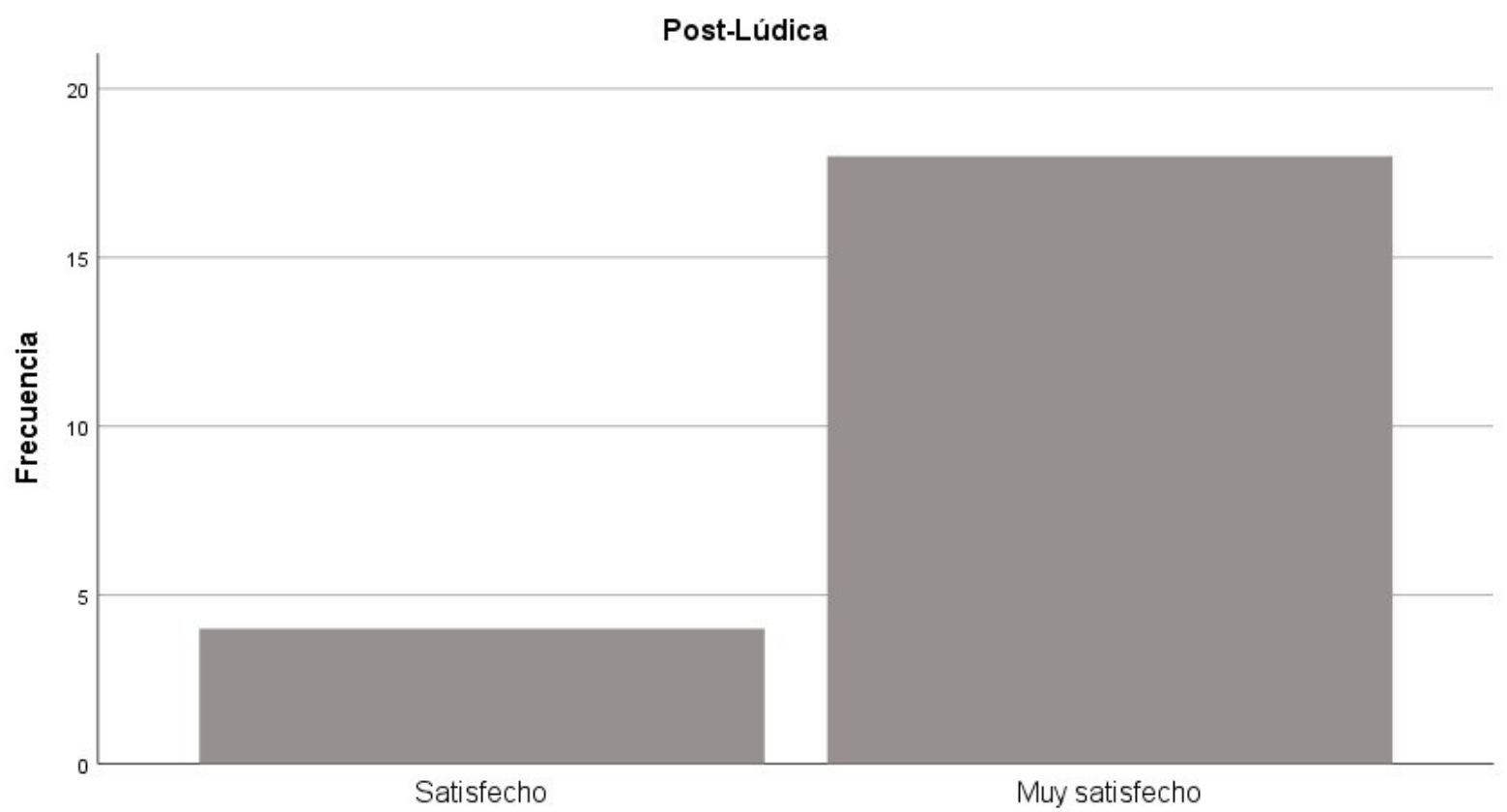

Post-Lúdica

Figura 3. Frecuencia de la variable satisfacción poslúdica. Fuente: Autores.

Considerando que existe diferencia entre el antes y el después de la aplicación de "Captura la idea", y, con el fin de probar la hipótesis nombrada previamente, se realizó la prueba Wilcoxon para muestras relacionadas.
Dado que el $p$-valor dio 0,027 (ver Tabla 5), se infiere que existe diferencia significativa y, por lo tanto, se rechaza la hipótesis nula. 
Leidy Tatiana Alvao-Saenz, Juliana Quintero-Salazar, Angie Marcela Ramírez Rubio

Captura la idea: Actividad lúdica para la enseñanza y fortalecimiento del pensamiento de diseño

Tabla 5

Prueba de Wilconxon

\begin{tabular}{lc}
\hline \multicolumn{2}{c}{ Estadísticos de pruebaa } \\
\hline \multicolumn{2}{c}{ Postlúdica - Prelúdica } \\
\hline$Z$ & $-2,217 \mathrm{~b}$ \\
Sig. asintótica(bilateral) &, 027 \\
a. Prueba de rangos con signo de Wilcoxon & \\
b. Se basa en rangos negativos. & \\
\hline
\end{tabular}

Fuente: Autores.

Con el fin de conocer el porcentaje de mejora de cada uno de los ítems, se realizó la Tabla 6, en donde se encuentra que el mínimo porcentaje de mejora está dado en la pregunta 12: "El tiempo que se le dedicó a la temática fue el óptimo", con 2,4\%. Esto debido a que los participantes expresaron que hora y media no era suficiente para la apropiada realización de todas las actividades. Por su parte, el ítem que presenta mayor porcentaje de mejora es el 7, el cual hace referencia a la capacidad de diseñar un producto. Esto como resultado a la puesta en práctica de la metodología y a la creación de prototipos y la divulgación de las ideas de negocios.

Tabla 6

Resultados promedio por ítem y aplicación del indicador de mejora

\begin{tabular}{ccccc}
\hline Pregunta & Prelúdica & Poslúdica & Diferencia & \% Mejora \\
\hline 1 & 4,27 & 4,82 & 0,55 & $12,8 \%$ \\
2 & 4,27 & 4,50 & 0,23 & $5,3 \%$ \\
3 & 4,05 & 4,59 & 0,55 & $13,5 \%$ \\
4 & 3,86 & 4,52 & 0,66 & $17,1 \%$ \\
5 & 3,77 & 4,52 & 0,75 & $19,9 \%$ \\
7 & 4,00 & 4,41 & 0,41 & $10,2 \%$ \\
8 & 2,82 & 3,82 & 1,00 & $35,5 \%$ \\
9 & 3,86 & 4,50 & 0,64 & $16,5 \%$ \\
10 & 3,68 & 4,27 & 0,59 & $16 \%$ \\
11 & 4,05 & 4,68 & 0,64 & $15,7 \%$ \\
12 & 3,73 & 4,55 & 0,82 & $22 \%$ \\
13 & 3,73 & 3,82 & 0,09 & $2,4 \%$ \\
14 & 3,95 & 4,45 & 0,50 & $12,6 \%$ \\
15 & 4,18 & 4,45 & 0,27 & $6,5 \%$ \\
\hline Promedio & 3,64 & 4,55 & 0,91 & $25 \%$ \\
\hline
\end{tabular}

Fuente: Autores.

Dado lo anterior, es importante revisar en qué categoría del 1 al 5 (donde 1 es en total desacuerdo, y 5, en total acuerdo) se encuentra cada pregunta de las encuestas realizadas pre- y poslúdica. En la categoría 1 no se halla ningún ítem. Por otro lado, en la clase 2 en la prelúdica se encuentra el apartado 7: "De acuerdo con la información adquirida en clase usted está en la capacidad de diseñar un producto". Este resultado se puede dar debido a que la teoría sin la puesta en práctica no es suficiente para el desarrollo de las habilidades creativas.
Así mismo, en la clase 3, en la prelúdica se hallan ocho ítems, que se subdividen en:

a) Los relacionados con la posición del estudiante respecto a la clase magistral $(5,8,11,15)$. Al encontrarse estos ítems en esta categoría, se deja en evidencia que los alumnos no se sienten lo suficientemente atraídos, motivos y estimulados intelectualmente.

b) Los relacionados a la metodología impartida (4, 9, 12, 13) muestran que el procedimiento usado en clase tiene deficiencias en la trasmisión del conocimiento, debido a que es muy metódico y el alumno es solo un receptor del conocimiento, lo que lleva a que su participación sea poca o nula.

De igual manera, en la clase 3 en la poslúdica se ubica el ítem 7: "De acuerdo con la información adquirida en clase usted está en la capacidad de diseñar un producto". Este puntaje tiene una mejora del 35,5\% respecto a la encuesta anterior, pero aun así deja en evidencia que pretender que con una sesión de hora y media el alumno se sienta completamente preparado para el diseño del producto no es posible, puesto que se le están brindando las nociones básicas y una metodología que con la práctica lo harán todo un experto. Por consiguiente, el desarrollo de esta competencia se debe estimular en diversos momentos durante su carrera. De manera similar el ítem 12: "El tiempo que se le dedicó a la temática fue el óptimo". Esta fue la mayor realimentación que se le hizo a la lúdica, debido a que el tiempo que está cronometrado por cada actividad generaba que los participantes se sintieran presionados.

Seguidamente, en la categoría 4. En la clase magistral se encuentran seis preguntas (1, 2, 3, 6, 10 y 14), el mayor puntaje promedio fue 4,27. Esto demuestra que la metodología que se usa actualmente es buena, pero se puede mejorar con el uso de estas herramientas lúdicas. Por su parte, la clase con la aplicación de la herramienta tuvo 13 preguntas dentro de la categoría 4, lo que muestra el alto grado de aceptación que presentó, pues se fortaleció la hipótesis planteada. Cabe aclarar que no se encontró ningún ítem en la sección 5 , Totalmente de acuerdo, esto como resultado de que ambas metodologías pueden seguir mejorando. Finalmente, en promedio se obtuvo un progreso del $15 \%$ respecto a la clase magistral.

\section{Discusión y conclusiones}

Esta investigación permite concluir que la actividad de aprendizaje activo con enfoque lúdico "Captura la idea" favorece la percepción del método enseñanzaaprendizaje en la materia de núcleo profesional de Ingeniería Industrial Administración de Operaciones I en el tema del diseño del producto. Esta hipótesis se pudo comprobar con la prueba de Wilcoxon y con el cálculo 
Leidy Tatiana Alvao-Saenz, Juliana Quintero-Salazar, Angie Marcela Ramírez Rubio Captura la idea: Actividad lúdica para la enseñanza y fortalecimiento del pensamiento de diseño

del indicador de mejora. Dado lo anterior, se reconoce la actividad lúdica como herramienta de uso pedagógica que puede mejorar el proceso de enseñanza-aprendizaje yque propicia la adquisición significativa de conocimiento y el desarrollo físico y comunicativo de los alumnos.

Teniendo en cuenta las respuestas dadas en el cuestionario, así como las sugerencias realizadas por los participantes, es necesario realizar un ajuste en el tiempo de la lúdica, ya sea proporcionar una duración mayor para cada una de las fases, o reorganizar las actividades de manera tal que puedan ser realizadas en una hora y media, que es la duración habitual de una clase.

Cabe destacar que esta actividad lúdica puede ser desarrollada en otros programas sin inconveniente, puesto que los tipos de clientes y sus respectivas necesidades son conocidos en el contexto estudiantil, $y$, además, cada una de las metodologías usadas se explica desde cero.

Esta investigación solo evalúa la percepción del estudiante respecto al método enseñanza-aprendizaje en Administración de Operaciones en el tema de DT. En futuras investigaciones se podría evaluar si hay mejoría en la apropiación del conocimiento a través del uso de esta estrategia lúdica, así como Marín-González et al. (2010) y Montoya (2014) lo han realizado en otras áreas.

Este trabajo confirma que el uso de actividades lúdicas es útil en el ámbito pedagógico debido a que los estudiantes sienten que la clase es más estimulante, agradable y llama su atención en mayor medida que la clase magistral. Así mismo, su participación aumenta significativamente y las actividades cambian su rol de receptor por el de agente activo en su proceso de aprendizaje.

Entre las diferencias de este trabajo respecto a los anteriores se encuentra el modelo de aplicación de DT seleccionado. Se usó el modelo $6 \mathrm{E}$, debido a su uso frecuente en salones de clases y considerando su pertinencia; además, es un modelo actualizado y tiene momentos definidos más claramente desde la perspectiva de las autoras.

De acuerdo con la revisión bibliográfica realizada, no es de conocimiento de las autoras que haya otra lúdica enfocada en DT que profundice en aspectos estadísticos en cuanto a la validación de la herramienta, y compare el uso de esta frente a la clase magistral convencional.

\section{Agradecimientos}

Agradecemos a los estudiantes de Ingeniería Industrial de la Universidad de Ibagué que participaron en la elaboración y aplicación de esta actividad lúdica, "Captura la idea". De igual forma se da un especial agradecimiento al Semillero de Aplicación de Lúdicas en Ingeniería (SALI) de la Universidad de Ibagué, por el apoyo y la orientación brindados.

\section{Referencias}

Aguilar-Fernández, M., Delgado-Rodríguez, A., García-Jarquín, B. y Acosta-Gonzaga, E. (2017). Conocimiento e innovación tecnológica en la ingeniería industrial. Revista de Ingeniería Industrial, 1(1), 19-40.

Alaminos, A. y Castejón, J. L. (2006). Elaboración, análisis e interpretación de encuestas, cuestionarios y escalas de opinión. Editorial Marfil S.A.

Albert, M. (2007). La investigación educativa: claves teóricas (J. Manuel, ed.). McGraw-Hill.

Barreto, J., Teherán, G., Turizo, E. y Londoño, N. (2019). Diseño de productos y servicios: Flying mind. VII encuentro de la Red Iddeal.

Boden, M. A. (1998). Creativity and Artificial Intelligence. Artificial Intelligence, 103(1-2), 347-356. https://doi. org/10.1016/S0004-3702(98)00055-1

Brown, T. y Wyatt, J. (2010). Design Thinking for Social Innovation. Essentials of Social Innovation. https:// ssir.org/articles/entry/design_thinking_for_social_ innovation

Escamilla, J.,Fuerte, K., Venegas, E., Fernández, K., Elizondo, J. y Román, R. (2016). Gamificación. Observatorio de Innovación Educativa del Tecnológico de Monterrey. 1-36. http://eduteka.icesi.edu.co/pdfdir/edutrendsgamificacion.pdf

Frias-Navarro, D. (2019). Apuntes de consistencia interna de las puntuaciones de un instrumento de medida. https://www.uv.es/friasnav/AlfaCronbach.pdf

Hernández, R., Fernández, C. y Baptista, M. (2014). Metodología de la investigación. Mcgraw-Hill/ Interamericana Editores. http://observatori o.epacartagena.gov.co/wp-content/uploads/20 17/08/metodologia-de-la-investigacion-sexta-edi cion.compressed.pdf

Kaplan, R. y Saccuzzo, D. (2006). Pruebas psicológicas: Principios, aplicaciones y temas. (Sexta Ed.). Thomson.

Marín-González, Y., Montes, J. O., Hernández-Riaño, H. E. y López-Pereira, J. M. (2010). Validación de la lúdica como herramienta metodológica complementaria en la enseñanza del método de producción tradicional y del método de producción de la teoría de restricciones (TOC) para el manejo de los 
Leidy Tatiana Alvao-Saenz, Juliana Quintero-Salazar, Angie Marcela Ramírez Rubio

Captura la idea: Actividad lúdica para la enseñanza y fortalecimiento del pensamiento de diseño

entornos multitarea. Ingenieria y Universidad, 14(1), 97-115.

Montoya, M., Monsalve, J. C. y Gaviria, J. M. (2014). Aplicación de un caso de estudio para la enseñanza de ingeniería de requisitos basado en lúdica en pregrado. Encuentro Internacional de Educación en Ingeniería ACOFI 2014. https://www.researchgate. net/publication/317837825

Pombo, F. y Tschimmel, K. (2005). Sapiens and Demens in Design Thinking-Perception as Core. Proceedings of the 6th International Conference of the European Academy of Design EAD. https://www.researchgate. net/publication/228878635

Ramírez, D. (2019). Importancia del diseño en la ingeniería. https://utelesup.edu.pe/blog-ingenieria-civil-ydesarrollo-inmobiliario/importancia-del-disenoen-la-ingenieria/

Rauth, I., Köppen, E., Jobst, B. y Meinel, C. (2010). Design Thinking: An Educational Model Towards Creative Confidence. DS 66-2: Proceedings of the 1st International Conference on Design Creativity (ICDC 2010).

Rodríguez, D. y Rodríguez, A. (2013). Innovación por design thinking: Creatividad Para los negocios. https://www. academia.edu/40238365/Innovación_por_Design_ Thinking_Creatividad_para_los_negocios

Ruiz, L., Gordo, M., Fernández, M., Boza, A., Cuenca, L., Alarcón, F. y Alemany, M. (2015). Implementación de actividades de aprendizaje y evaluación para el desarrollo de competencias genéricas: un caso práctico de aplicación de técnicas de Pensamiento de Diseño, y evaluación mediante rúbricas, de las competencias de Creatividad, Innovación y E. In-Red 2015 - Congreso Nacional de Innovación Educativa y Docencia en Red. https://doi. org/10.4995/INRED2015.2015.1639

Streiner,D.L.(2003). Being Inconsistent AboutConsistency: When Coefficient Alpha Does and Doesn't Matter. Journal of personality assessment, 80(3), 217-222. https://doi.org/10.1207/S15327752JPA8003_01

Tschimmel, K., Loyens, D., Soares, J., Oraviita, T., Barroca, A., Marinova, B., Santos, J., Carenzo, M. y Manzini, S. (2017). Design Thinking Applied to Education y Training. www.d-think.eu

Valdrich, T. y Cândido, A. (2018). Mapa de empatia como proposta de instrumento em estudos de usuários: aplicaçâo realizada na biblioteca pública de Santa Catarina. Revista ACB: Biblioteconomia em Santa Catarina, 23(1), 107-124.
Zandoval, F. y Zilber, M. (2014). Innovation and Business Model: A Case Study About Integration of Innovation Funnel and Business Model Canvas. Revista Brasileira de Gestao de Negocios, 16(53), 616637. 
- Lienzo Canvas

\section{MODELO DE NEGOCIO CANVAS}

NOMBRE DEL GRUPO :

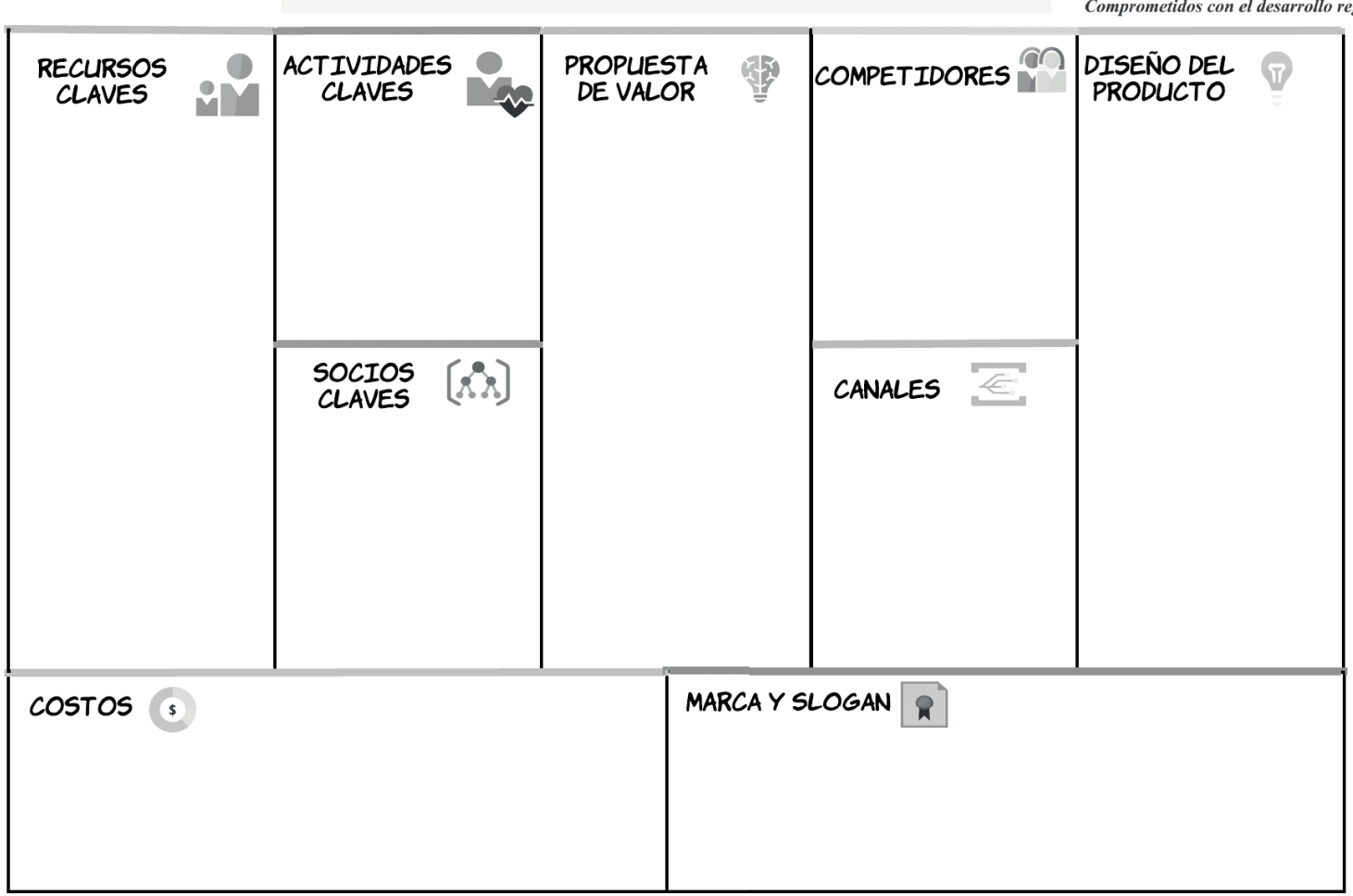

Figura 4. Modelo Business Canvas. Fuente: Adaptado de Zandoval y Zilber (2014).

- Características de los clientes

\section{Caracteristicas de los Clientes}

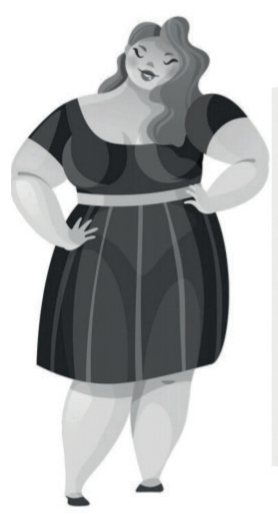

Mujer adulta sedentaria, con sobrepeso.

Descomplicada, versátil y amante de las compras. La misma tiene poder adquisitivo medio

Figura 5. Ficha de las características 1. Fuente: Autores.
Caracteristicas de los Clientes.

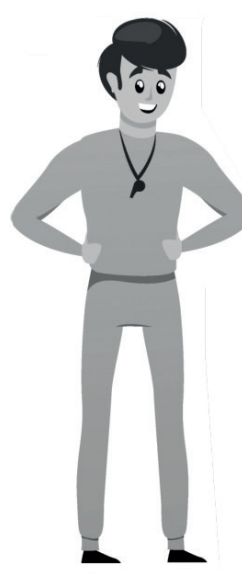

Adulto amante del ejercicio,con régimen de alimentación definido. Apasionado por la tecnología y con nivel adquisitivo medio. 
Leidy Tatiana Alvao-Saenz, Juliana Quintero-Salazar, Angie Marcela Ramírez Rubio

Captura la idea: Actividad lúdica para la enseñanza y fortalecimiento del pensamiento de diseño

Caracteristicas de

los Clientes.

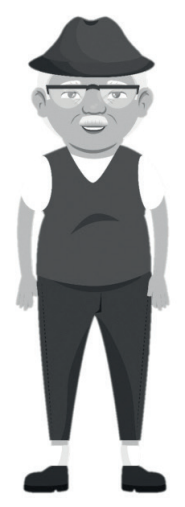

Hombre de tercera edad.

Racional, metódico y organizado. El mismo es resistente al cambio y su nivel adquisitivo es bajo.
Figura 7. Ficha de las características 3. Fuente: Autores.

Caracteristicas de

los Clientes

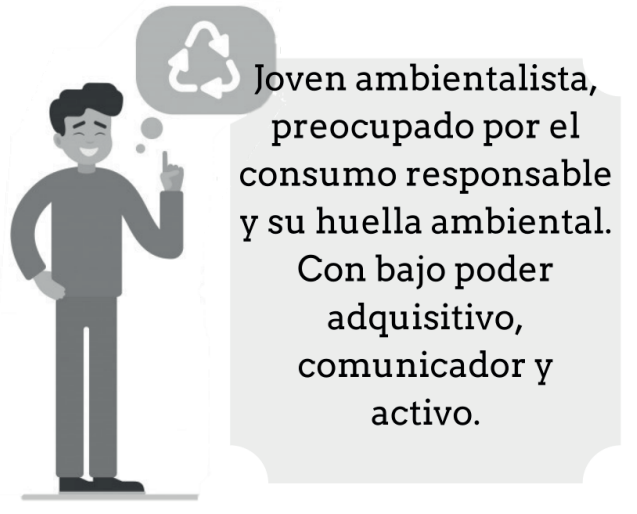

Figura 8. Ficha de las características 4. Fuente: Autores.

Caracteristicas de los Clientes

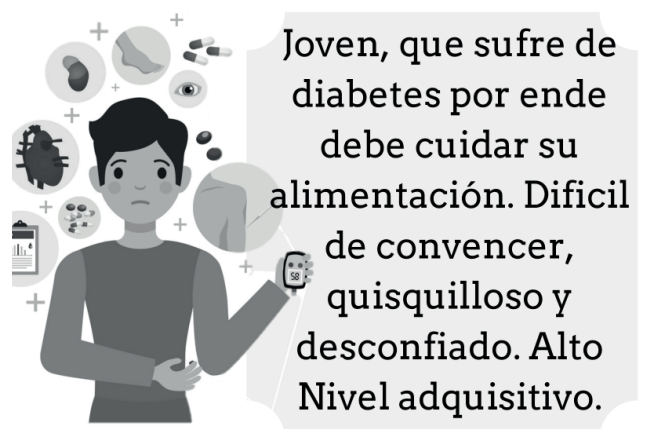

Figura 9. Ficha de las características 5. Fuente: Autores.
Caracteristicas de los Clientes.

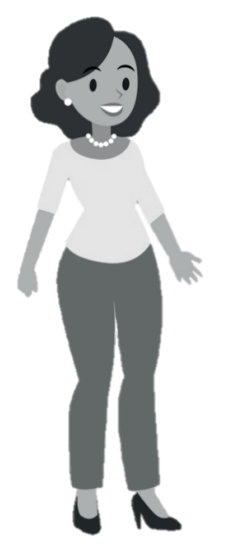

Mujer adulta que busca ser aceptada socialmente, que realiza multiples actividades y se preocupa por el bienestar de su familia. Su poder adquisitivo es medio

Figura 10. Ficha de las características 6. Fuente: Autores.

Caracteristicas de los Clientes.
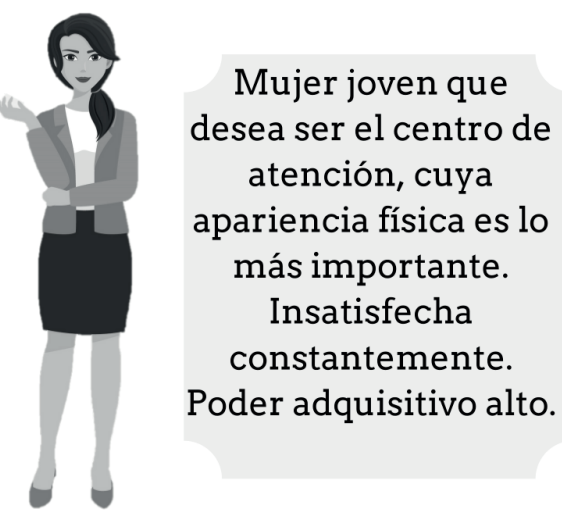

Figura 11. Ficha de las características 7. Fuente: Autores.

Caracteristicas de los Clientes.

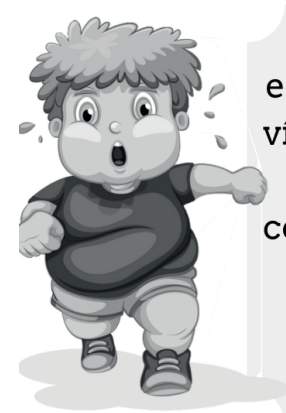

Niño obeso con especial gusto por los vídeos y la tecnología. Con alto nivel de compras gracias a sus padres. Mimado y caprichoso. Nivel adquisitivo alto.

Figura 12. Ficha de las características 8. Fuente: Autores.

I+D Revista de Investigaciones ISSN 2256-1676 / ISSN en línea 2539-519X

Volumen 16 Número 1 Enero-Junio de 2021 pp. 28-44

40 
Leidy Tatiana Alvao-Saenz, Juliana Quintero-Salazar, Angie Marcela Ramírez Rubio

Captura la idea: Actividad lúdica para la enseñanza y fortalecimiento del pensamiento de diseño

- Deseos de los clientes

Necesidad o Deseo:

Descarsar mejor en las noches

Figura 13. Ficha de necesidades o deseos 1. Fuente: Autores.

Necesidad o Deseo:

Tener mayor energia durante el dia

Figura 14. Ficha de necesidades o deseos 2. Fuente: Autores.

Necesidad o Deseo:

Diferenciación de los demais

Figura 15. Ficha de necesidades o deseos 3. Fuente: Autores.

Necesidad o Deseo:

Seguridad al salir a la calle

Figura 16. Ficha de necesidades o deseos 4. Fuente: Autores.

Necesidad o Deseo:

Aspecto Saludlable y Radiante

Figura 17. Ficha de necesidades o deseos 5. Fuente: Autores.

Necesidad o Deseo:

Experiencias Nuevas

Figura 18. Ficha de necesidades o deseos 6. Fuente: Autores.

Necesidad o Deseo:

Alimentarse Rapido y Sano

Figura 19. Ficha de necesidades o deseos 7. Fuente: Autores.
Necesidad o Deseo:

Caminar tranguiloumente

Figura 20. Ficha de necesidades o deseos 8. Fuente: Autores.

- Modelo brainwriting

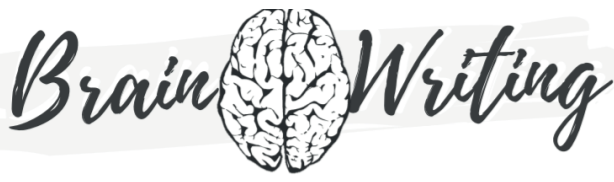

Nombre Grupo

Caracteristicas del eliente

Deseo/Necesidad

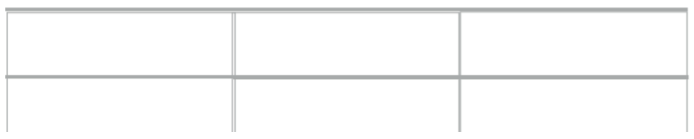

Figura 21. Modelo de Brainwriting. Fuente: Autores.

- Mapa de empatía

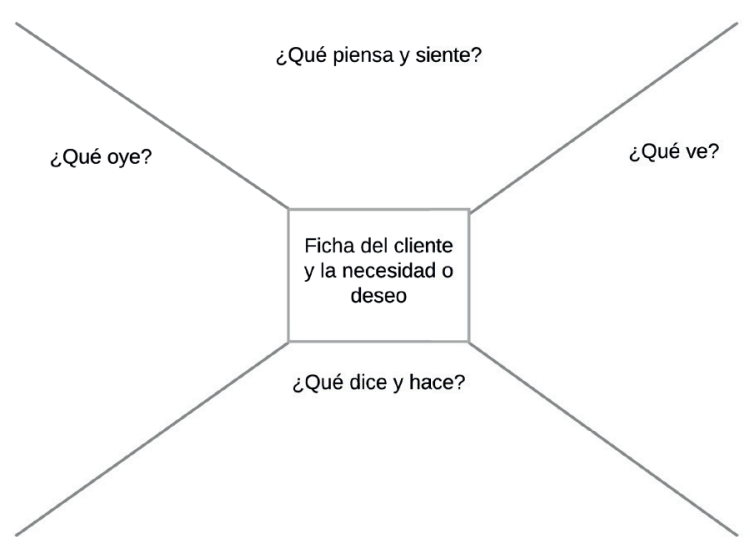

Figura 22. Mapa de empatía. Fuente: Adaptado de Valdrich y Cândido (2018).

I+D Revista de Investigaciones ISSN 2256-1676 / ISSN en línea 2539-519X

Volumen 16 Número 1 Enero-Junio de 2021 pp. 28-44

41 
Leidy Tatiana Alvao-Saenz, Juliana Quintero-Salazar, Angie Marcela Ramírez Rubio

Captura la idea: Actividad lúdica para la enseñanza y fortalecimiento del pensamiento de diseño

\section{Anexo II: Encuesta prelúdica}

\section{Bunerasiat de Ibagué}

\section{Encuesta De Validación Diseño Del Producto}

El propósito de esta encuesta es conocer su percepción respecto al método de enseñanza que se utilizó para impartir la temática diseño del producto en la clase de Administración de operaciones I del programa de ingeniería Industrial de la Universidad de Ibagué. Por favor responder las siguientes afirmaciones del 1 al 5 , teniendo en cuenta que 1 es totalmente de desacuerdo y 5 es totalmente de acuerdo.

1. Las explicaciones dadas en clase facilitaron la comprensión de la temática.

2. La información suministrada en clase fue clara y concisa.

(1) (2) (4) 5

3. La forma en que se abordó la temática cumplió con mis expectativas.

(1) (2) (4) 5

4. La metodología de enseñanza facilitó la compresión del tema

(1) (3) (4)

(1) (2) $(4$

5. La metodología usada en la enseñanza llamó su atención

6. El conocimiento adquirido en el módulo: diseño del producto es apropiado.

7. De acuerdo con la información adquirida en clase usted está en la capacidad de diseñar un producto.

8. La clase que recibió fue agradable y lo motiva a seguir profundizando en el tema

(1) (3) 5

9. La forma de abordar la clase profundiza los contenidos de la temática diseño del producto.

10. El docente promovió su participación en clase

11. La interacción entre los estudiantes fue la adecuada

(1) (2) $(3) 5$

(1) $23(5$

\section{(1) (2) 45}

(1) (2) (3) 5

(1) (2) (4) 5

12. El tiempo que se le dedicó a la temática fue el óptimo.

(1) (2) (4) 5

13. La clase cumplió con sus expectativas

(1) (2) $(3)$

14. El material utilizado dentro de la clase es el apropiado

(1) (2) (4) 5

(1) (2) (4) 5

15. El curso es intelectualmente estimulante

Fuente: Autores. 


\section{Anexo III: Encuesta poslúdica}

\section{Q Q Universidad $\Xi_{\text {de Ibagué }}$}

\section{Encuesta De Validación Diseño Del Producto}

El propósito de esta encuesta es facilitar la evaluación de la lúdica "Captura la idea". La misma tiene como fin facilitar el aprendizaje del tema diseño del producto dictado en la clase de Administración de operaciones I de la Universidad de Ibagué. Por favor responder las siguientes afirmaciones del 1 al 5 , teniendo en cuenta que 1 es totalmente de desacuerdo y 5 es totalmente de acuerdo.

1. Las explicaciones dadas en clase facilitaron la comprensión de la temática.

2. La información suministrada en clase fue clara y concisa.

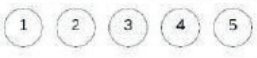

3. La forma en que se abordó la temática cumplió con mis expectativas.

4. La metodología de enseñanza facilitó la compresión del tema

(1) (2) (4)

5. La metodología usada en la enseñanza llamó su atención

6. El conocimiento adquirido en el módulo: diseño del producto es apropiado.

De acuerdo con la información adquirida en clase usted está en la capacidad de diseñar un producto.

8. La clase que recibió fue agradable y lo motiva a seguir profundizando en el tema

(1) (2) (4) 5

La forma de abordar la clase profundiza los contenidos de la temática diseño del producto.

10. El docente promovió su participación en clase

11. La interacción entre los estudiantes fue la adecuada

(1) (2) (4) 5

12. El tiempo que se le dedicó a la temática fue el óptimo.

(1) (2) (4)

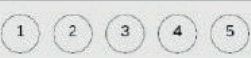

13. La clase cumplió con sus expectativas

(1) (2) (3) 5

(1) (2) (4) 5

14. El material utilizado dentro de la clase es el apropiado

(1) (2) (3) 5

15. El curso es intelectualmente estimulante

(1) (2) (3) 5

16. Que aspectos positivos le observo a la lúdica. (Por favor responder a conciencia)

17. Que aspectos negativos le observo a la lúdica. (Por favor responder a conciencia)

Fuente: Autores. 
Leidy Tatiana Alvao-Saenz, Juliana Quintero-Salazar, Angie Marcela Ramírez Rubio

Captura la idea: Actividad lúdica para la enseñanza y fortalecimiento del pensamiento de diseño

\section{Anexo IV: Aplicación de la lúdica}

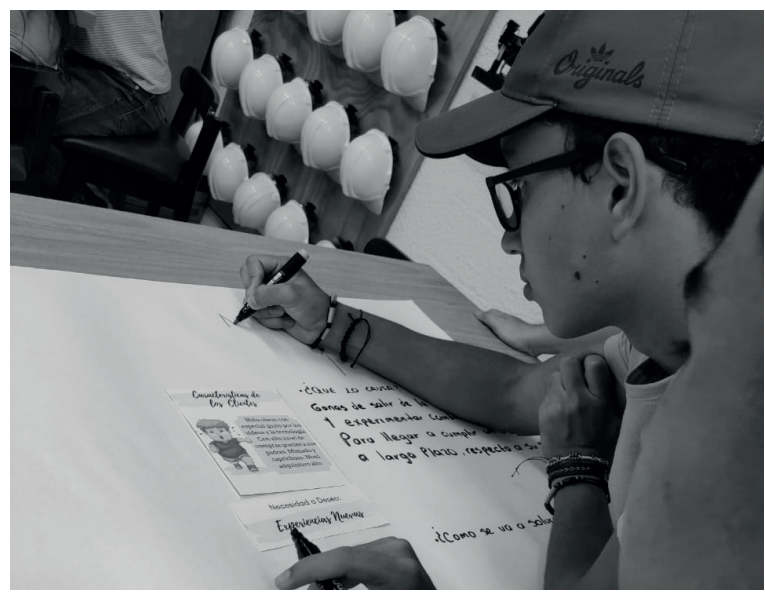

Figura 23. Aplicación del mapa de empatía. Fuente: Autores.

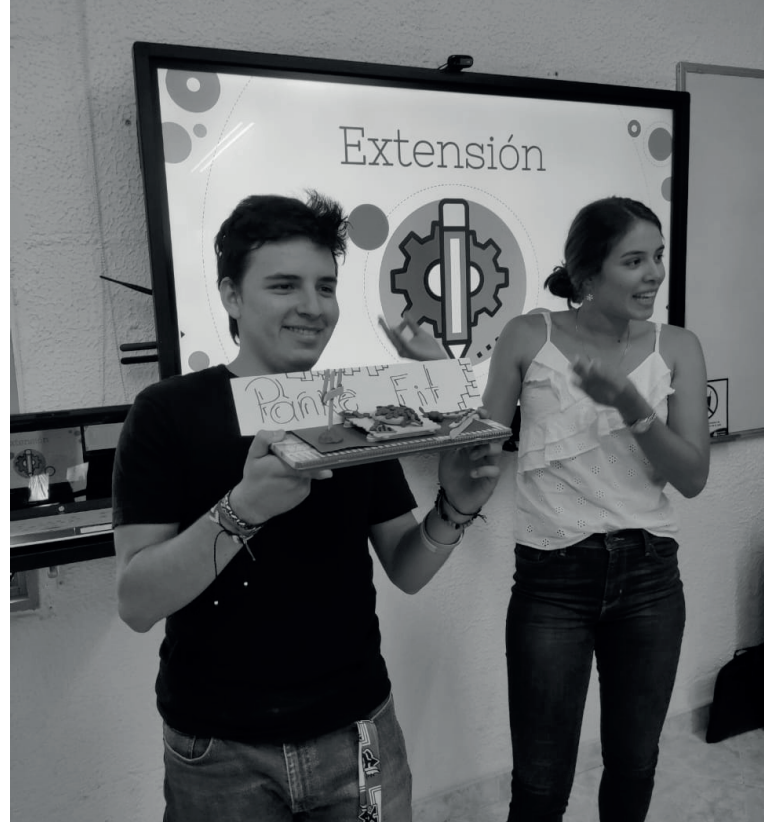

Figura 24. Exposición de los proyectos. Fuente: Autores.

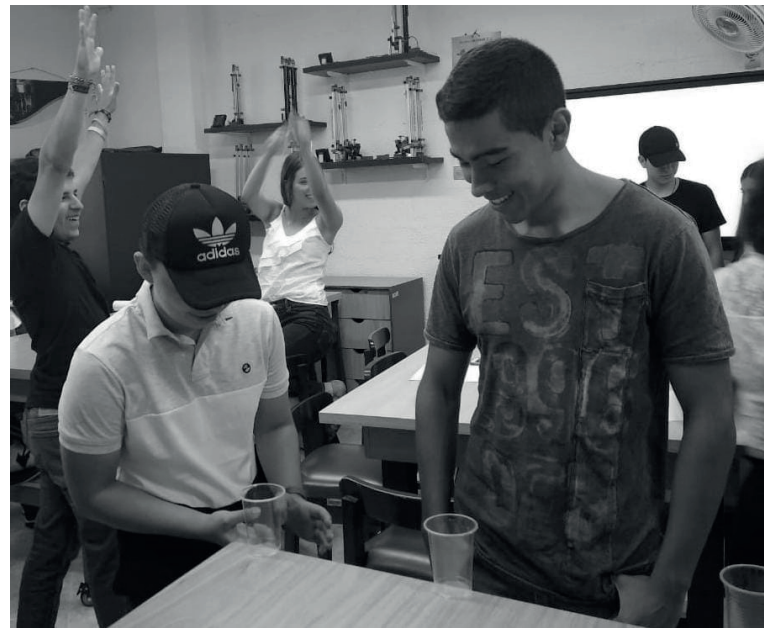

Figura 25. Aplicación de la actividad de los vasos. Fuente: Autores.

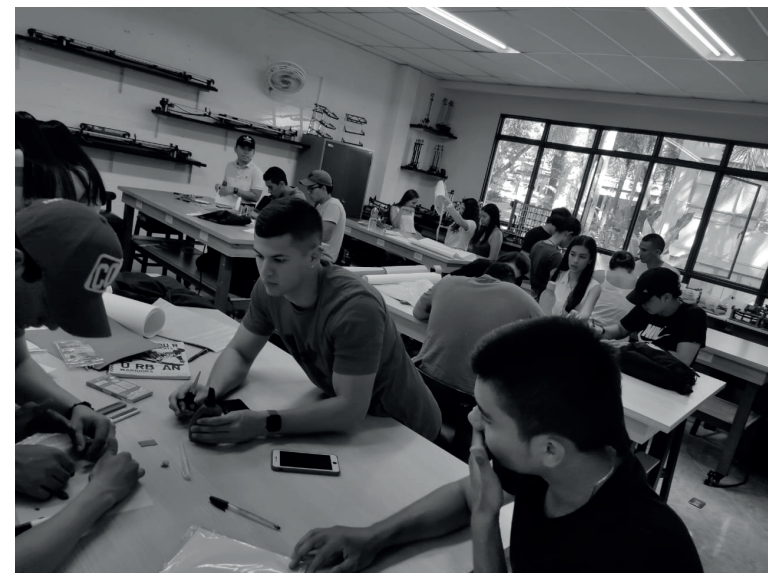

Figura 26. Estudiantes desarrollando la idea. Fuente: Autores.

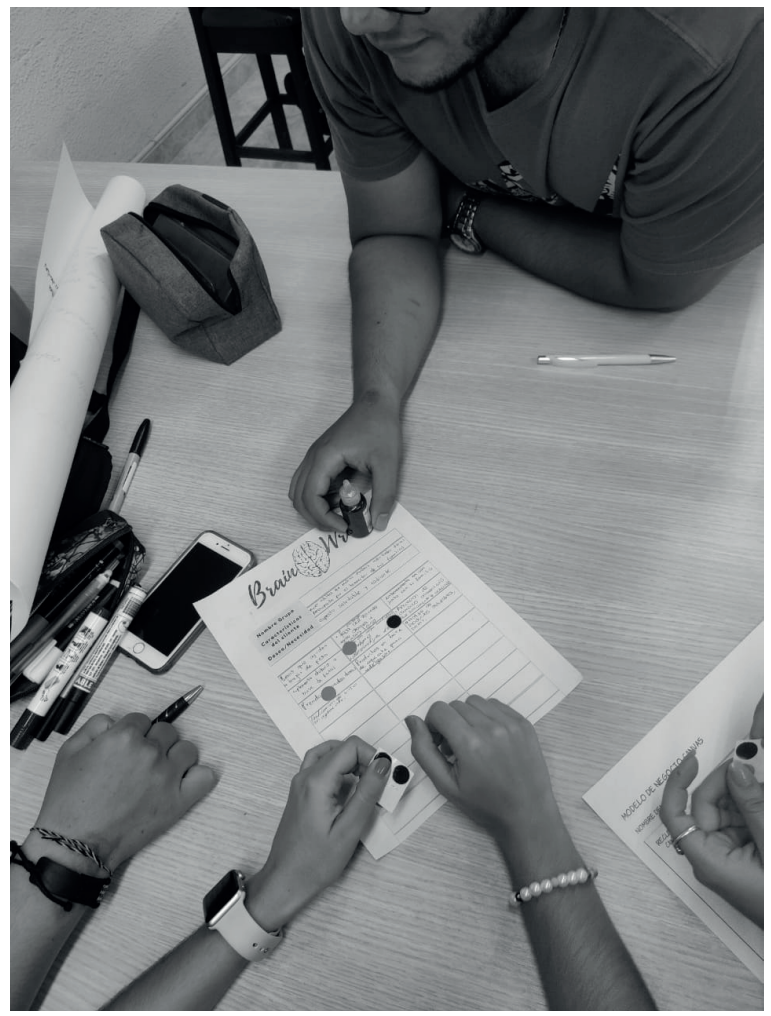

Figura 27. Desarrollando la actividad de brainwriting. Fuente: Autores. 